$\therefore \quad$ DOE/60/10030--1-PF. 3

\title{
NATURAL CONVECTION HEAT EXCHANGERS FOR SOLAR WATER HEATING SYSTEMS
}

Technical Progress Report

August 1, 1995 to September 30, 1995

Jane H. Davidson

Department of Mechanical Engineering

University of Minnesota

Minneapolis, MN 55455

Prepared for the United States Department of Energy

Under Contract No. DE-FG36-94G010030 


\section{DISCLAIMER}

This report was prepared as an account of work sponsored by an agency of the United States Government. Neither the United States Government nor any agency thereof, nor any of their employees, makes any warranty, express or implied, or assumes any legal liability or responsibility for the accuracy, completeness, or usefulness of any information, apparatus, product, or process disclosed, or represents that its use would not infringe privately owned rights. Reference herein to any specific commercial product, process, or service by trade name, trademark, manufacturer, or otherwise does not necessarily constitute or imply its endorsement, recommendation, or favoring by the United States Government or any agency thereof. The views and opinions of authors expressed herein do not necessarily state or reflect those of the United States Government or any agency thereof. 


\section{DISCLAIMER}

Portions of this document may be illegible electronic image products. Images are produced from the best available original document. 


\title{
NATURAL CONVECTION HEAT EXCHANGERS FOR SOLAR WATER HEATING SYSTEMS
}

\author{
DE-FG36-94G010030 \\ Jane H. Davidson \\ University of Minnesota
}

\author{
Reporting Period: $\quad$ August 1, 1995 - September 30, 1995 \\ Project Personnel: Jane H. Davidson \\ Scott Dahl, Graduate Research Assistant
}

\section{Project Objectives:}

The goals of this project are 1) to develop guidelines for the design and use of thermosyphon heat exchangers external to the storage tank in solar domestic water heating systems and 2) to establish appropriate modeling and testing criteria for evaluating the performance of systems using this type of heat exchanger.

\section{Model Development}

Thermosyphon mass flow rate in a side-arm heat exchanger depends on density differences and hydraulic resistance throughout the water loop. Using a 1-D assumption, the thermosyphon flow rate can be determined by equating frictional losses to total hydrostatic pressure:

$$
\mathrm{R} \frac{\dot{\mathrm{m}}^{2}}{\rho}=\left.\int_{0}^{\mathrm{H}} \rho(\mathrm{T}) \mathrm{gdz}\right|_{\text {Tank }}-\left.\int_{0}^{\mathrm{H}} \rho(\mathrm{T}) \mathrm{gdz}\right|_{\mathrm{HX}} .
$$

Frictional losses on the left-hand-side of eqn. (1) include shear pressure drop on the thermosyphon side of the heat exchanger and across any piping connecting the heat exchanger to the tank. Frictional losses in the tank are negligible. To increase thermosyphon flow, frictional losses can be reduced by using larger diameter pipes and by carefully designing inlets and outlets on the tank and heat exchanger. Water temperature in the heat exchanger affects frictional losses through its affect on viscosity. The effect of water temperature on friction factor is shown in Figure 1. Note that these curves apply to fully developed flow. In the short heat exchangers proposed by industry, the flow is probably not fully developed. In this case, friction factors can be much higher. 


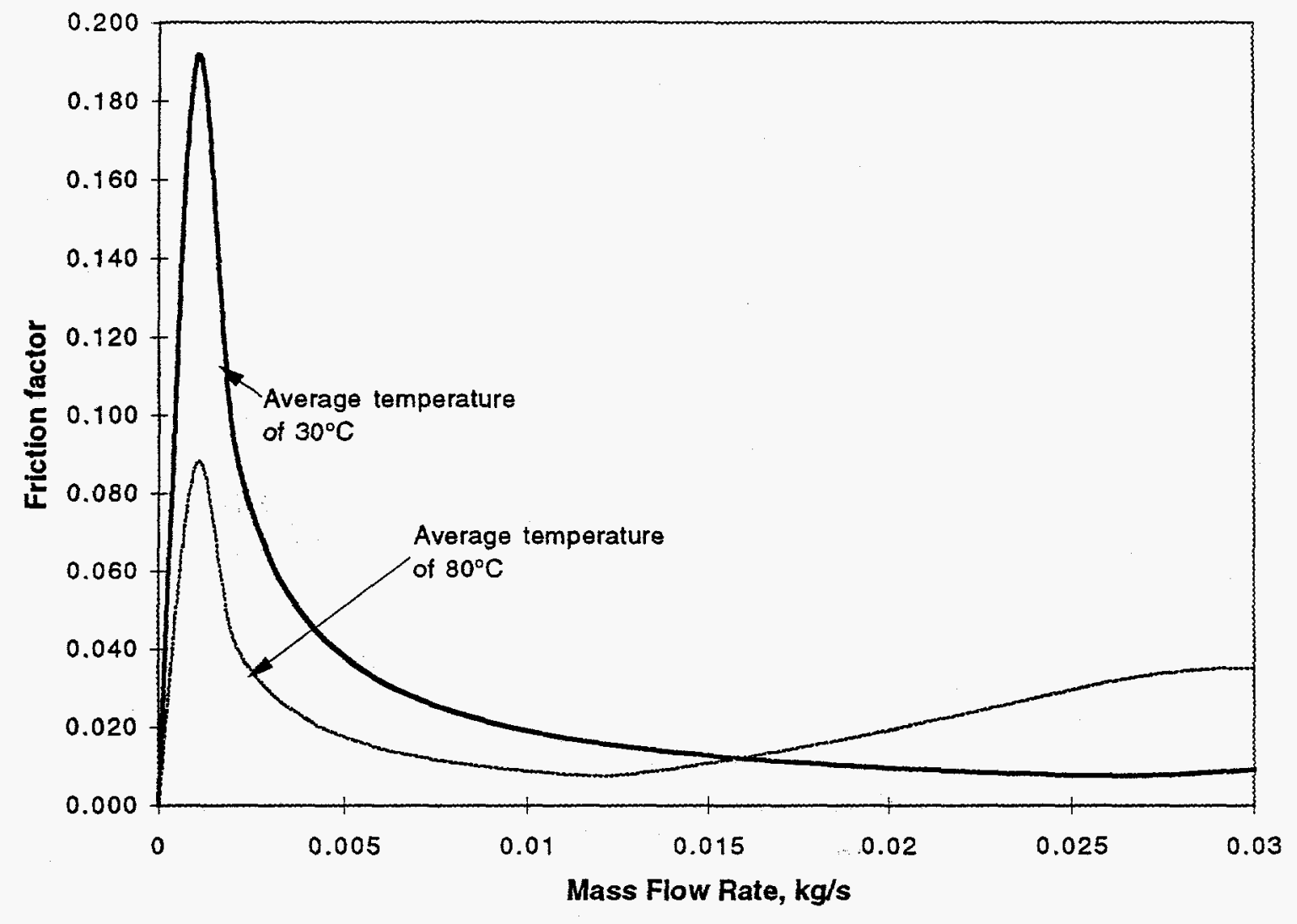

Figure 1. Fanning friction factor as a function of flow rate for water in $1.9 \mathrm{~cm}$ diameter pipe (based on a correlation by Churchill).

The pressure difference on the right-hand-side of eqn. (1) can be viewed as the driving force for the thermosyphon flow. Height $\mathrm{H}$ is the vertical distance from location where cold water exits the storage tank to the position on the tank where hot fluid returns from the heat exchanger. The heat exchanger itself may be shorter than the distance between outlet and inlet on the tank, but both integrals on the right-hand-side of eqn. (1) must be evaluated over this height. With the same heat exchanger and fixed collector operating conditions, thermosyphon flow rate decreases as temperature of the water storage tank increases. It increases as temperature in the heat exchanger rises.

Elliot and Harrison (1993) proposed a correlation for thermosyphon mass flow rate based on the difference in average temperature of water in the tank and the temperature of fluid entering the heat exchanger from the collector,

$$
\dot{\mathrm{m}}_{\mathrm{t}}=0.0028 \cdot\left(\mathrm{T}_{\mathrm{h}, \mathrm{i}}-\mathrm{T}_{\mathrm{avg}, \tan \mathrm{k}}\right)^{0.5} .
$$

Since this temperature difference does not characterize the temperature distribution in the heat exchanger, it is not representative of the driving force on the right-hand-side of eqn. (1) and is not expected to be of general use in predicting thermosyphon flow rate.

We attempted to predict thermosyphon flow rate in the Thermodynamics coil-in-shell heat exchanger (Fraser, 1992) and in a two-pass tube-in-shell heat exchanger tested at the University of Minnesota with this temperature difference. Figure 2 is a plot of thermosyphon flow rate as a function of $\left(T_{h, i}-T_{a v g, t a n k}\right)$, for the coil-in-shell heat exchanger. These data were obtained with an isothermal storage tank. The results of four experiments are shown. Collector flow rates used are 
$0.01,0.02$ and $0.03 \mathrm{~kg} / \mathrm{s}$. Experiments were conducted with the tank at $19^{\circ} \mathrm{C}, 21^{\circ} \mathrm{C}$ and $30^{\circ} \mathrm{C}$. As expected, no single correlation is possible.

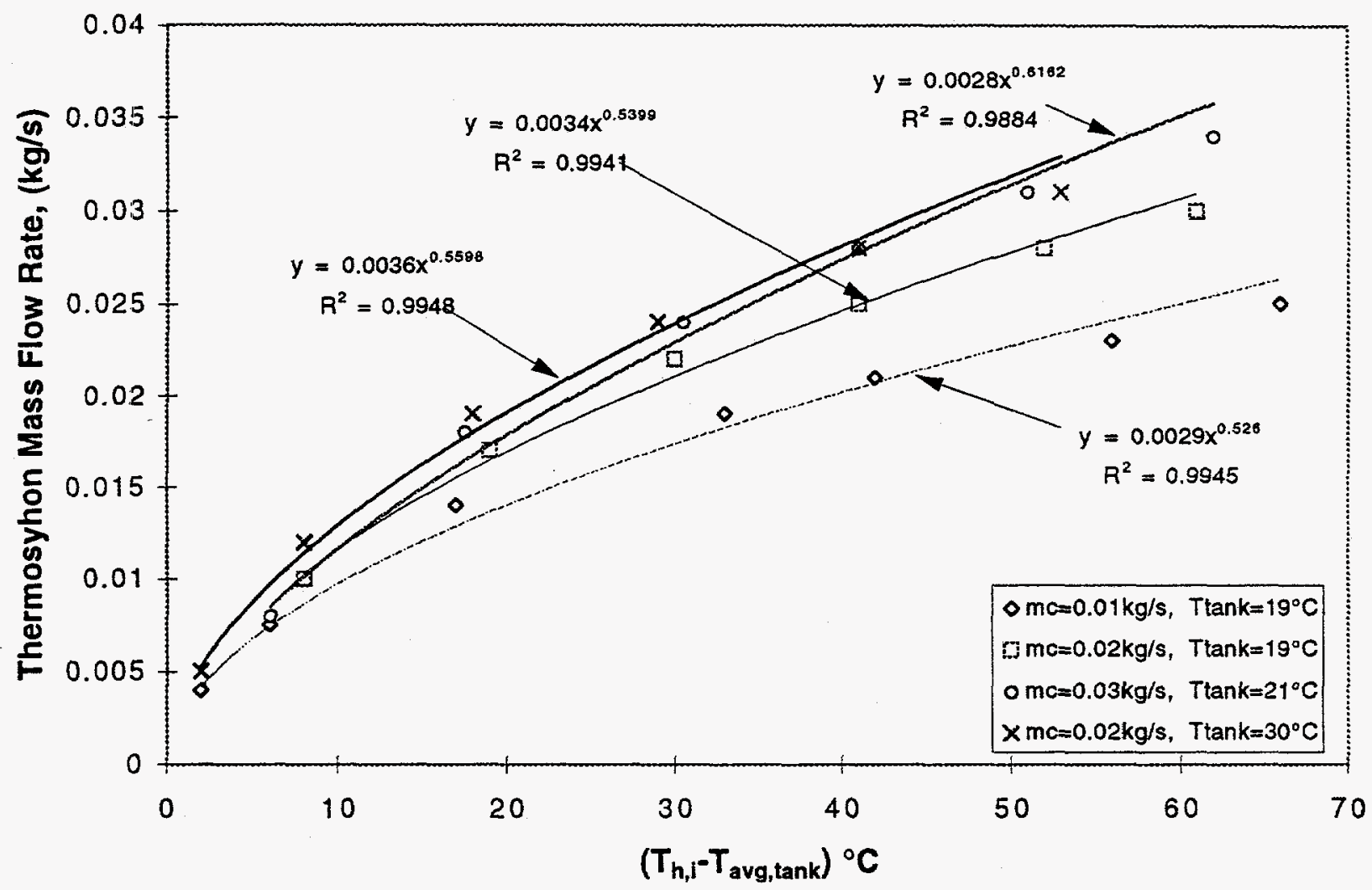

Figure 2. Thermosyphon mass flow rate versus $\left(\mathrm{T}_{\mathrm{h}, \mathrm{i}}-\mathrm{T}_{\mathrm{avg} \text {,ank }}\right)$ for coil-in-shell heat exchanger with the tank maintained at a uniform temperature. Data taken from Fraser (1992).

Further evidence of the inadequacy of the proposed correlation is illustrated in Figure 3. In this figure, experimental values of thermosyphon mass flow rate are plotted versus $\left(\mathrm{T}_{\mathrm{h}, \mathrm{i}}-\mathrm{T}_{\mathrm{avg}, \mathrm{tank}}\right)$ for the tube-in-shell heat exchanger tested at the University of Minnesota. The data were obtained with a collector flow rate of $0.03 \mathrm{~kg} / \mathrm{s}(\approx 0.5 \mathrm{gpm})$. The test consisted of two parts. During the first part of the test, the tank temperature was maintained at a uniform temperature of $25^{\circ} \mathrm{C}$ while the temperature of the collector fluid (50\% ethylene glycol) was increased every 30 minutes in increments of $15^{\circ} \mathrm{C}$ from $25^{\circ} \mathrm{C}$ to $95^{\circ} \mathrm{C}$. The tank was held isothermal by the slow addition of cold mains water to the bottom of the tank as warm water from the top of the tank was dumped. The second part of the test began after 200 minutes when the collector fluid was $95^{\circ} \mathrm{C}$. At this point in the test, the cold mains water was disconnected from the tank and the tank was allowed to heat up. Collector outlet temperature, $\mathrm{T}_{\mathrm{b}, \mathrm{i}}$, was held constant . 


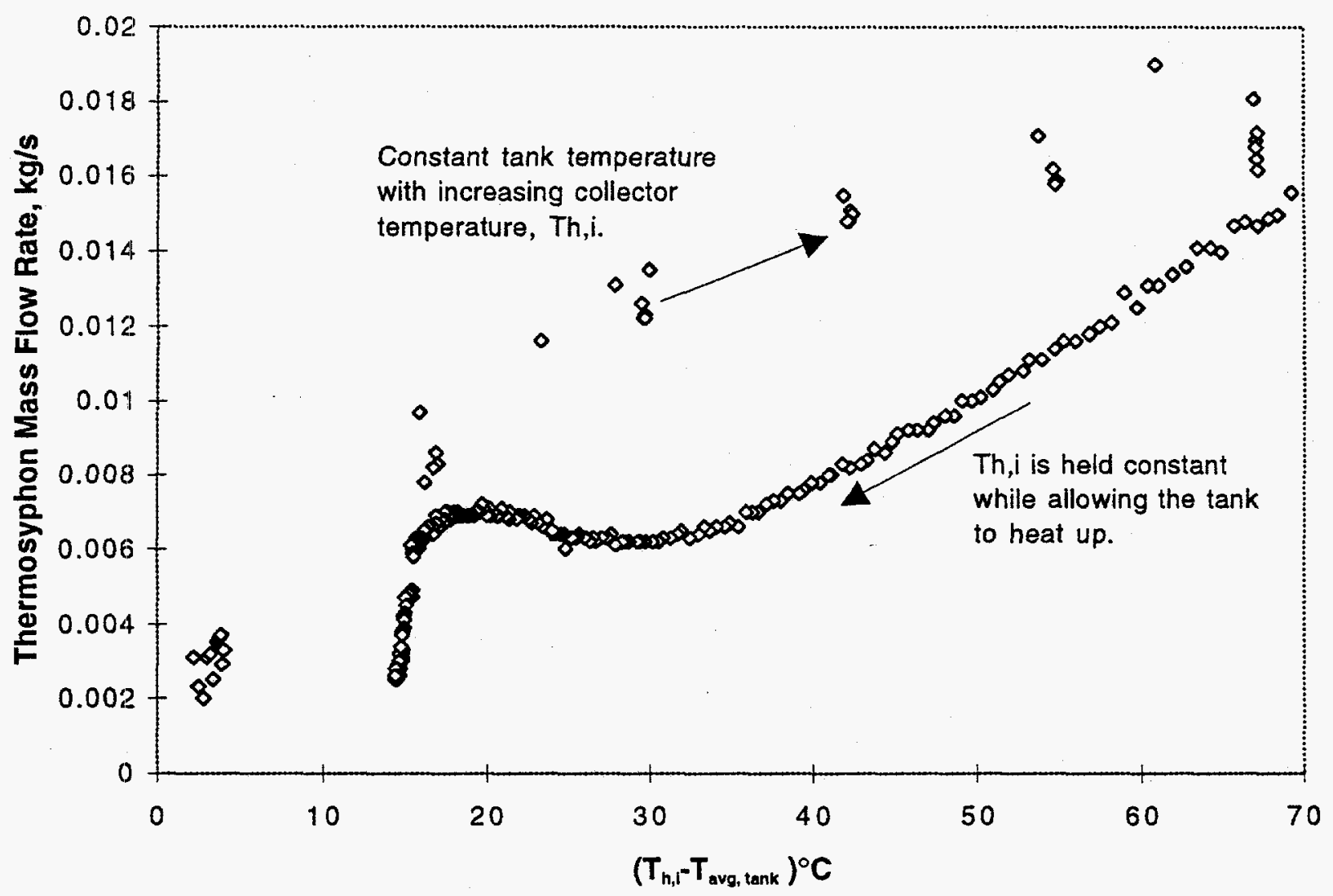

Figure 3. Thermosyphon mass flow rate versus $\left(T_{h, i}-T_{\text {avg,tank }}\right)$ for the two-pass, tube-in-shell heat exchanger. Collector flow rate is $0.03 \mathrm{~kg} / \mathrm{s}(\approx 0.5 \mathrm{gpm})$.

As expected, with an isothermal tank, thermosyphon mass flow rate increased as $T_{h, j}$ was increased. The scatter in the data during this first part of the test is due to transients that occurred with each step increase in $T_{b, i}$. In the second part of the test, mass flow rate decreased as the average tank temperature and the level of stratification increased.

Several other correlations were considered in attempts to predict thermosyphon flow rate with temperature differences in the system. Table 1 displays a listing of the other temperature correlations tried. None of the attempted correlations was successful.

Table 1 Temperature differences used in attempts to predict thermosyphon flow rate.

\begin{tabular}{|l|l|}
\hline Correlation & Description \\
\hline $\mathrm{T}_{\mathrm{h}, \mathrm{i}}-\sum \mathrm{T}_{\mathrm{i}} \mathrm{y}_{\mathrm{i}} / \Sigma \mathrm{y}_{\mathrm{i}}$ & $\begin{array}{l}\text { Tried to use a weighted temperature in the storage } \\
\text { tank }\end{array}$ \\
\hline $\mathrm{T}_{\mathrm{h}, \mathrm{i}}-\mathrm{T}_{\mathrm{c}, \mathrm{o}}$ & \\
\hline $\mathrm{T}_{\mathrm{h}, \mathrm{i}}-\mathrm{T}_{\mathrm{c}, \mathrm{i}}$ & \\
\hline
\end{tabular}

A more appropriate parameter for predicting thermosyphon flow rate is the driving hydrostatic pressure difference on the right-hand-side of eqn. (1). Calculation of this term requires knowledge of the vertical temperature distribution on the thermosyphon side of the heat exchanger 
as well as in the water storage tank. For the two-pass, tube-in-shell heat exchanger tested at the University of Minnesota, the vertical temperature distribution in the tank is known. The pressure in the tank was calculated in two ways. In the first method, the average tank temperature was used to determine a value for fluid density in the tank. In the second method, the density profile in the tank was determined from the measured temperature profile.

In a first attempt to determine hydrostatic pressure in the heat exchanger, we used a constant water density corresponding to a temperature equal to the average of the inlet and outlet water temperatures. Figure 4 is a plot of hydrostatic pressure within the water loop as a function of time during the test described earlier in the discussion of Figure 3. During the first part of the test when the tank was isothermal, there is no difference in calculations of hydrostatic pressure in the tank. Hydrostatic pressure in the heat exchanger dropped as the temperature of anti-freeze entering the exchanger was increased.

During the second part of the test, beginning 200 minutes after the start of testing, the hydrostatic pressure in the tank decreased as the tank heated up. The maximum error in hydrostatic head in the tank due to using the average tank temperature as opposed to the measured temperature distribution is $20 \mathrm{~Pa}$. Since $20 \mathrm{~Pa}$ is significant in terms of the driving pressure difference, subsequent calculations are made using the measured temperature distribution.

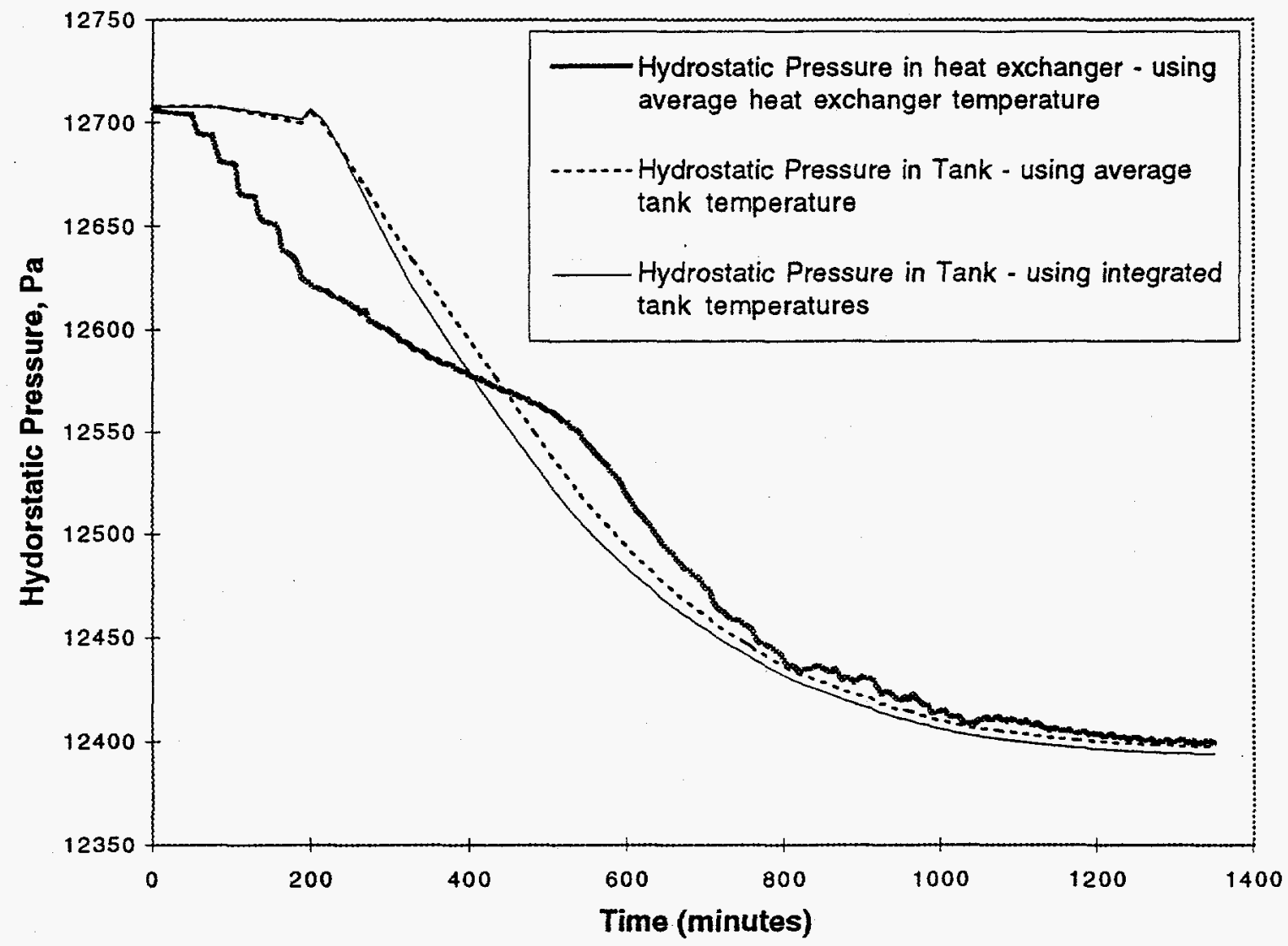

Figure 4. Hydrostatic pressure in the storage tank and heat exchanger as a function of time for the two-pass, tube-in-shell heat exchanger. Collector flow rate is $0.03 \mathrm{~kg} / \mathrm{s}(\approx 0.5 \mathrm{gpm})$.

The differences in hydrostatic pressures and the measured thermosyphon mass flow rate are plotted versus test duration in Figure 5. At the beginning of the test, thermosyphon flow was initiated as the hydrostatic driving force increased due to a step increase in collector loop temperature from $25^{\circ} \mathrm{C}$ to $40^{\circ} \mathrm{C}$. During the first part of the test, tank temperature was kept constant at $25^{\circ} \mathrm{C}$ and thermosyphon flow rate continued to increase as collector temperature was 
increased to $95^{\circ} \mathrm{C}$. After 200 minutes, hot water from the heat exchanger was no longer removed from the storage tank and the tank becomes thermally stratified. As the hydrostatic pressure in the tank decreased, the driving force for the thermosyphon flow decreased and thermosyphon flow rate fell.

After 400 minutes of testing, the calculated hydrostatic pressure difference in the water loop fell below zero. A negative value of the driving pressure difference suggests that the thermosyphon flow was reversed. However at this point in the test, thermosyphon flow rate determined from an energy balance on the heat exchanger is $0.008 \pm 0.0005 \mathrm{~kg} / \mathrm{s}$. As a check to determine if a flow reversal actually occurred, dye was added to the water flow in a clear pipe installed between the exit at the top of the heat exchanger and the tank. Flow visualization confirmed that the flow never reversed direction. The discrepancy between the hydrostatic pressure and the measured flow rate indicates that one of the terms in the driving force was incorrectly assessed. We are confident that hydrostatic pressure in the water tank is reasonable. The most likely source of error is the assumption that density of the fluid in the heat exchanger can be based on a water temperature equal to the average of measured inlet and outlet temperatures.

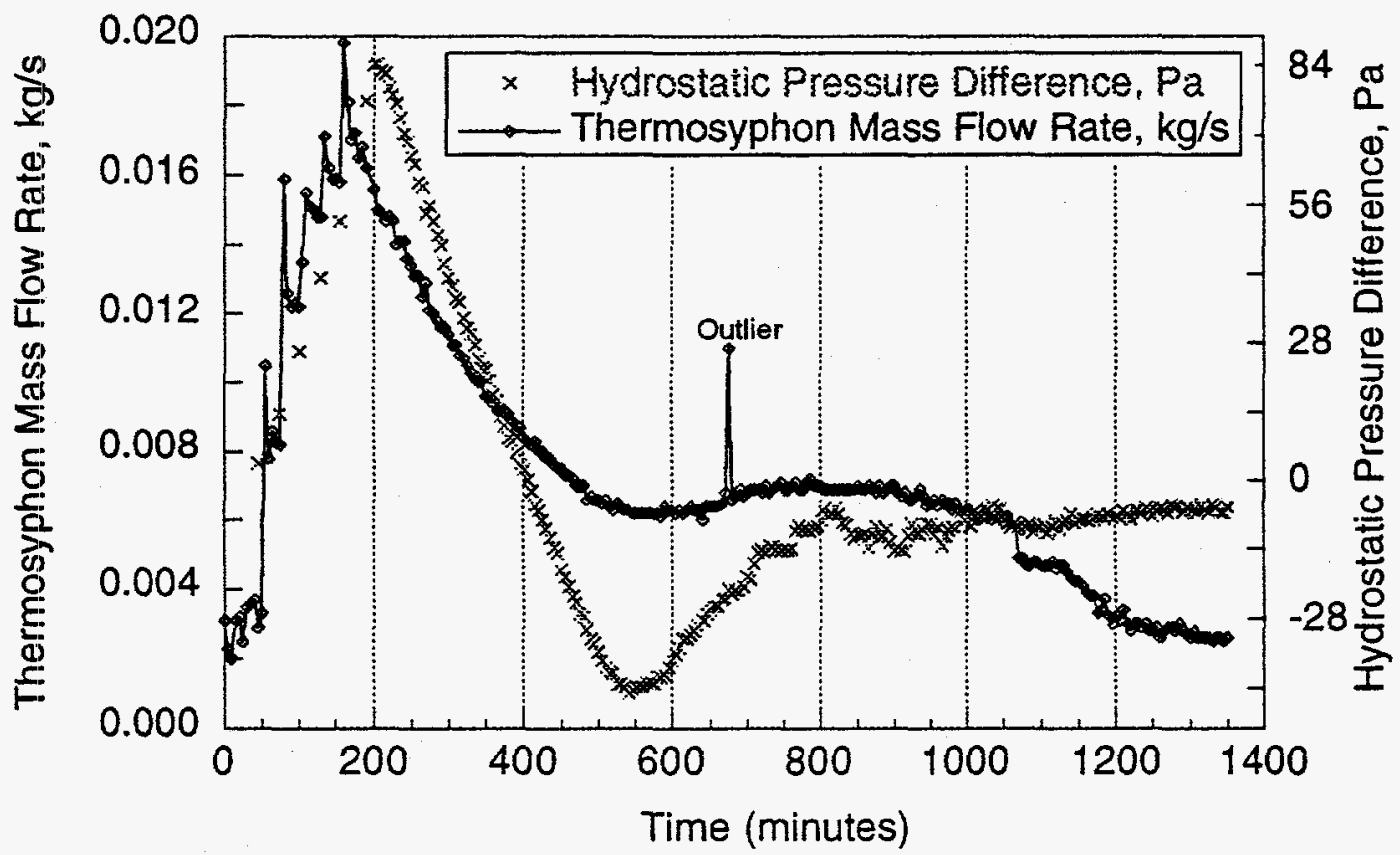

Figure 5. Thermosyphon flow rate and hydrostatic driving force, , i.e. the driving force on the right-hand-side of eqn. (1), versus time for an experiment with the two-pass, tube-inshell heat exchanger. Collector flow rate is $0.03 \mathrm{~kg} / \mathrm{s}$.

To more accurately asses the vertical temperature profile on the water side of the heat exchanger, we made some preliminary measurements with thermocouples attached to the outside wall of the copper shell. The data were taken with a collector flow rate of $0.03 \mathrm{~kg} / \mathrm{s}$ with $\mathrm{T}_{\mathrm{h}, \mathrm{j}}$ equal to $95^{\circ} \mathrm{C}$ and an average tank temperature of $67^{\circ} \mathrm{C}$. This measured profile is compared to an assumed linear profile in Figure 6 . The assumption of a linear profile in this case causes a underestimate of the driving hydrostatic pressure of $37 \mathrm{~Pa}$. Based on the pressures shown in Figure 6, this error is significant and cannot be ignored.

Further testing is required, with a fully instrumented heat exchanger, to investigate how the temperature profile varies over the range of operating conditions. Since 1-D models of the thermosyphon heat exchanger depend on correct assessment of the hydrostatic pressure in the water loop, it is imperative that we continue efforts to understand the processes taking place in the water loop. 


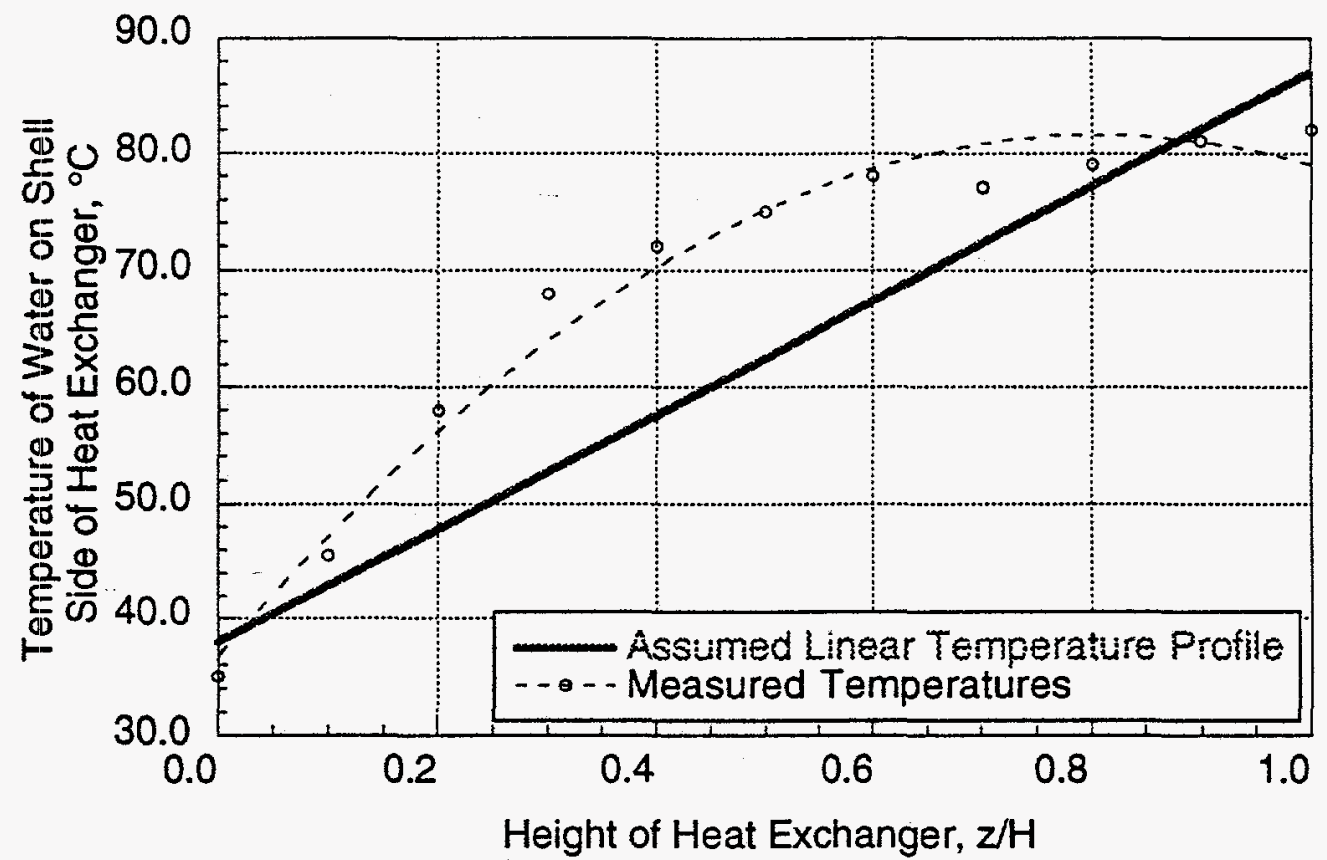

Figure 6. Measured and predicted temperature profiles for the two-pass, tube-in-shell heat exchanger as a function of heat exchanger height. The data were obtained with a collector flow rate of $0.03 \mathrm{~kg} / \mathrm{s}$ with $\mathrm{T}_{\mathrm{h}, \mathrm{i}}$ set to $95^{\circ} \mathrm{C}$ and an average tank temperature of $67^{\circ} \mathrm{C}$.

\section{Use ICEPAK to model heat exchanger}

In a preliminary effort to model the longitudinal temperature variation in the two-pass, tubein-shell heat exchanger, we used the finite element analysis program ICEPAK sold by Fluid Dynamics International. This program handles 3-D geometries and incorporates both natural and forced convection. We found that a very fine mesh would be required to accurately predict temperature and velocity fields and to avoid divergence problems in the coupled energy and momentum equations. The problem was solved only when the length of the heat exchanger was reduced to 1/4 the original height and with only a single tube inside the shell. The simplified model which had about 50,000 elements took approximately 5 hours of CPU time on a Silicon Graphics machine with two $150 \mathrm{MHz}$ processors. The full scale heat exchanger is estimated to require approximately 200,000 elements, which would require nearly 24 hours of CPU time. The large amount of computational time required for such a geometry demonstrates the need for a simple model to predict the performance of the systems.

\section{TRNSYS Modeling}

Scott Dahl spent a week at the University of Wisconsin working on TRNSYS models of the natural convection heat exchanger. John Avina wrote two user sections for TRNSYS to model natural convection heat exchanger systems, a "simple model" based on Fraser's work (1992) (TYPE 67) and a "detailed model" of the Thermodynamics coil-in-shell heat exchanger based on published heat transfer and flow correlations (TYPE 69). The tank model, TYPE 4, was modified (Now TYPE 68) to contain code which calculates the hydrostatic pressure in the storage tank. The user written codes for types 67,68 , and 69 had to be slightly modified because the initial work 
was all done on a UNIX system. With these modifications, we were able to reproduce Avina's results on the $\mathrm{PC}$.

A "steady-state" model, using TYPE 67 and 68, was used to predict the thermosyphon mass flow in the tube-in-shell heat exchanger with the tank at a constant temperature and varying $\mathrm{T}_{\mathrm{h}, \mathrm{j}}$ temperatures (essentially the first part of our tests). The collector, any auxiliary water heater, and water draws are not included in the model. Theoretical values of form losses for the connecting piping and measured values of modified effectiveness and pressure drop as functions of thermosyphon mass flow rate were used. Data were obtained at the University of Minnesota. Predicted thermosyphon flow rates were substantially higher than the measured values. Increasing the form losses by $100 \%$ corrected the discrepancy. Avina had to increase the frictional losses by $40 \%$ to obtain good agreement between the experimental and simulated flow rates in the coil-inshell heat exchanger. Although it may be possible to apply a correction factor to the theoretical friction factors and thus obtain agreement between predicted and measured values of flow rate in these simple tests, caution must be taken in assuming that the only modeling error is determination of pressure drop in the connecting piping. Correction of the pressure drop term can obscure other modeling errors (such modeling temperature distributions in the heat exchanger and/or tank) that may become important in modeling the performance of these systems in actual installations.

We also modified Avina's "transient model" to run on a PC and to model the tube-in-shell heat exchanger. The "transient" model is an annual simulation using weather data, hot water draws, auxiliary electric heat and collectors. The major differences between the system analyzed by Avina and ours (other than the heat exchanger) are the storage tank and auxiliary heating system. Avina specified an isothermal storage tank (single-node tank) with an external auxiliary heater. The University of Minnesota system includes a twelve-node tank with electric heater inside the solar storage tank. Using the modified deck, system performance was unrealistic. Neither Nathan Blair, the TRNSYS engineer, nor Scott could resolve this problems during the week Scott spent in Madison.

We plan to continue efforts to resolve problems in using the TRNSYS models.

\section{Future Activity}

Continued fundamental analysis of the thermosyphon heat exchanger is underway and modeling efforts have begun. We are currently working with two US manufacturers who are planning to market thermosyphon heat exchangers. Scott Dahl is preparing his proposal for his doctoral dissertation. 